University of Nebraska - Lincoln

DigitalCommons@University of Nebraska - Lincoln

Demonstration of a conceptual model for using LiDAR to improve the estimation of floodwater mitigation potential of Prairie Pothole Region wetlands

\author{
Shengli Huang \\ ASRC Research and Technology Solutions \\ Claudia Young \\ Earth Resources Technology (ERT), Inc. \\ Min Feng \\ Chinese Academy of Sciences \\ Karl Heidemann \\ USGS EROS \\ Matthew Cushing \\ SGT, Inc.
}

See next page for additional authors

Follow this and additional works at: https://digitalcommons.unl.edu/usgsnpwrc

Huang, Shengli; Young, Claudia; Feng, Min; Heidemann, Karl; Cushing, Matthew; Mushet, David M.; and Liu, Shuguang, "Demonstration of a conceptual model for using LiDAR to improve the estimation of floodwater mitigation potential of Prairie Pothole Region wetlands" (2011). USGS Northern Prairie Wildlife Research Center. 278.

https://digitalcommons.unl.edu/usgsnpwrc/278

This Article is brought to you for free and open access by the US Geological Survey at DigitalCommons@University of Nebraska - Lincoln. It has been accepted for inclusion in USGS Northern Prairie Wildlife Research Center by an authorized administrator of DigitalCommons@University of Nebraska - Lincoln. 


\section{Authors}

Shengli Huang, Claudia Young, Min Feng, Karl Heidemann, Matthew Cushing, David M. Mushet, and Shuguang Liu 


\title{
Demonstration of a conceptual model for using LiDAR to improve the estimation of floodwater mitigation potential of Prairie Pothole Region wetlands
}

\author{
Shengli Huang a,1, Claudia Young ${ }^{\mathrm{b}, 2}$, Min Feng ${ }^{\mathrm{c}, \mathrm{d}}$, Karl Heidemann ${ }^{\mathrm{e}}$, Matthew Cushing ${ }^{\mathrm{f}, 3}$, David M. Mushet ${ }^{\mathrm{g}}$, \\ Shuguang Liu ${ }^{\mathrm{e}, *}$ \\ ${ }^{a}$ ASRC Research and Technology Solutions, Contractor to the US Geological Survey (USGS) Earth Resources Observation and Science (EROS), 47914 252nd Street, \\ Sioux Falls, SD 57198, USA \\ ${ }^{\mathrm{b}}$ Earth Resources Technology (ERT), Inc., Contractor to the USGS EROS, 47914 252nd Street, Sioux Falls, SD 57198-0001, USA \\ 'State Key Laboratory of Resources and Environment Information System, Institute of Geographic Sciences and Natural Resources Research, Chinese Academy of Sciences, \\ Beijing 100101, China \\ ${ }^{\mathrm{d}}$ Department of Geography, University of Maryland, College Park, MD 20742, USA \\ e USGS EROS, 47914 252nd Street, Sioux Falls, SD 57198, USA \\ ${ }^{\mathrm{f}}$ SGT, Inc., Contractor to USGS EROS, 47914 252nd Street, Sioux Falls, SD 57198-0001, USA \\ ${ }^{\mathrm{g}}$ USGS Northern Prairie Wildlife Research Center, 8711 37th Street, SE, Jamestown, ND 58401, USA
}

\section{A R T I C L E I N F O}

\section{Article history:}

Received 9 July 2010

Received in revised form 15 December 2010

Accepted 24 May 2011

Available online 31 May 2011

This manuscript was handled by

K. Georgakakos, Editor-in-Chief, with the

assistance of Michael Bruen, Associate

Editor

\section{Keywords:}

Prairie Pothole Region

Wetland

Flood

LiDAR

Digital elevation

\begin{abstract}
S U M M A R Y
Recent flood events in the Prairie Pothole Region of North America have stimulated interest in modeling water storage capacities of wetlands and their surrounding catchments to facilitate flood mitigation efforts. Accurate estimates of basin storage capacities have been hampered by a lack of high-resolution elevation data. In this paper, we developed a $0.5 \mathrm{~m}$ bare-earth model from Light Detection And Ranging (LiDAR) data and, in combination with National Wetlands Inventory data, delineated wetland catchments and their spilling points within a $196 \mathrm{~km}^{2}$ study area. We then calculated the maximum water storage capacity of individual basins and modeled the connectivity among these basins. When compared to field survey results, catchment and spilling point delineations from the LiDAR bare-earth model captured subtle landscape features very well. Of the 11 modeled spilling points, 10 matched field survey spilling points. The comparison between observed and modeled maximum water storage had an $R^{2}$ of 0.87 with mean absolute error of $5564 \mathrm{~m}^{3}$. Since maximum water storage capacity of basins does not translate into floodwater regulation capability, we further developed a Basin Floodwater Regulation Index. Based upon this index, the absolute and relative water that could be held by wetlands over a landscape could be modeled. This conceptual model of floodwater downstream contribution was demonstrated with water level data from 17 May 2008.
\end{abstract}

Published by Elsevier B.V.

\section{Introduction}

With an area around $715,000 \mathrm{~km}^{2}$, the Prairie Pothole Region (PPR) of North America extends from north-central Iowa to central Alberta. The landscape of PPR is dotted with millions of topographic depressions created during the last glacial retreat, approximately 12,000 years ago (Winter, 1989). Wetlands within these depressions range in size from a fraction of a hectare to several square kilometers; most PPR wetlands are small with an estimated median of 0.16 ha, and are shallow with depths generally less than $1 \mathrm{~m}$ and varying in permanency (Sethre et al., 2005; Zhang et al.,

\footnotetext{
* Corresponding author. Tel.: +1 6055946168.

E-mail address: sliu@usgs.gov (S. Liu).

1 Work performed under USGS Contract G08PC91508.

2 Work performed under USGS Contract G10PC00044.

${ }^{3}$ Work performed under USGS Contract 08HQCN0005.
}

2009). While wetlands of the PPR are often viewed as isolated (closed) basins, many may connect to one another during wet conditions through the "fill and spill" mechanism (Winter and LaBaugh, 2003; van der Kamp and Hayashi, 2009). PPR wetlands vary from being shallow and temporary to deep and permanent, depending on topography and the water balance, which is determined by precipitation, evapo-transpiration, snowmelt runoff, groundwater exchange, and antecedent status of soil and depressional storage (Fang and Pomeroy, 2008; van der Kamp and Hayashi, 2009). In total, basins of the PPR have large storage capacities and thus can mitigate peak runoff during a flood event (Hayashi et al., 2003; Hubbard and Linder, 1986; Gleason and Tangen, 2008). For example, Godwin and Martin (1975) stated the numerous depressions in the northern glaciated prairie of North America collectively have a significant retention capacity, which prevents runoff from contributing to stream flow during snowmelt and storm events. Hubbard and Linder (1986) also 
concluded that 213 prairie wetlands in South Dakota, USA stored large quantities of water (equivalent to $31 \mathrm{~mm}$ of water over the entire study area) despite their small size $\left(2700 \mathrm{~m}^{2}\right.$ on average). This stored water is kept out of rivers and thus reduces downstream flooding.

Despite the importance of wetlands in flood control, the natural landscape of the PPR has been substantially filled, leveled, drained, and converted to agriculture since European settlement in the late 1800s; this has resulted in the loss of over half of the original 8 million hectares of wetlands (Dahl, 1990; Dahl and Johnson, 1991). Wetland depressions are important landscape features in the PPR; changes in drainage patterns in the prairie landscape due to human activity have been implicated as a cause for increased downstream flooding frequency and magnitude in recent years (Winter et al., 1984; LaBaugh et al., 1998; Rannie, 1980; Hubbard and Linder, 1986; Gleason et al., 2007). Due to concern over the reduction of flood mitigation services, interest in developing spatially distributed hydrological models to simulate the effects of wetland water storage has increased (Gleason et al., 2007; Gleason and Tangen, 2008).

Many attempts have been made to model wetland water storage services of the PPR wetlands (e.g., Godwin and Martin, 1975; Hubbard and Linder, 1986; Gleason et al., 2007); however, several difficulties remain in these efforts. First, due to the vast number of wetlands in the PPR, it is difficult to quantify the amount of water volume stored in every depression. As a result, storage information is primarily calculated for large water bodies, such as lakes or wetlands in a specific, small area (Minke, 2009). Second, highresolution elevation data is typically not available, and researchers have had to rely on Digital Elevation Models (DEMs) with resolutions up to $10 \mathrm{~m}$ to model water storage; these coarse resolutions are usually inadequate to capture the detailed relief of the region (Gleason et al., 2007). The relationship of wetland area to volume or interception area has been applied to estimate wetland basin storage characteristics with support from remotely sensed data such as the National Wetlands Inventory (NWI); however, the application, limitations, and biases associated with such approaches are not well defined (Gleason et al., 2007). Third, in previous modeling efforts, the phenomenon of wetlands becoming interconnected at high water levels, which influences water storage capacity in prairie wetlands, were not taken into account (Gleason et al., 2007).

The objective of this paper is to propose and demonstrate a conceptual model for using high-resolution Light Detection And Ranging (LiDAR) data to improve the estimation of floodwater mitigation potential of wetland basins of the PPR. To accomplish this work, we applied hydrologic modeling techniques to further the understanding of surface flow characteristics within the PPR based upon a $0.5 \mathrm{~m}$ bare-earth DEM derived from LiDAR data. This
DEM was used to delineate each wetland catchment area as well as the position and elevation of basin spilling points. From each catchment and its spilling point, we modeled maximum water storage capacity. The maximum water storage considered individual basins and their connectivity. The model output was compared to field survey data for accuracy assessments. Maximum water storage capacity of basins, however, does not translate into the realistic floodwater regulation capability; we, therefore, developed an index to estimate the absolute and relative floodwater that could be held by topographic depressions under different flood events. This conceptual model was demonstrated using water level conditions derived from a one-time LiDAR collection event on 17 May 2008. The realistic floodwater mitigation capability of a basin relies on the antecedent water volume prior to a flood event, when water levels could be lower or higher than our collection date. However, the use of water levels derived from the 17 May $2008 \mathrm{Li}$ DAR acquisition demonstrates the applicability of our techniques to the improvement of floodwater mitigation estimates when antecedent water volume is known or can be modeled.

\section{Study area}

Our study area, a $6.4 \mathrm{~km} \times 30.6 \mathrm{~km}\left(196 \mathrm{~km}^{2}\right)$ block, is located in Stutsman County of North Dakota (Fig. 1). The western portion of this area is within a glacial stagnation moraine known as the Missouri Coteau. The Missouri Coteau is a hummocky, knoband-kettle landscape formed when melting ice blocks were buried by a thick superglacial drift. The subsequent collapse of the drift into vacated voids after ice blocks melted created numerous depressions. These depressions filled with runoff and groundwater, resulting in the innumerable wetlands that characterize the poorly drained topography of the PPR. The eastern portion of the area is within the glaciated plains (also known as a drift plain). As opposed to the Missouri Coteau where glaciers were stalled for long periods of time, glaciers in this area retreated at a fairly even rate leaving behind an undulating plain of low-relief ground moraine. Wetlands in the drift plain are less numerous and generally shallower than those in the stagnation moraine of the Missouri Coteau.

Historically, vegetation within the study area is mixed grass prairie. However, the landscape has been substantially altered, and the majority of the prairie grasslands have been converted to agricultural croplands, which in 2008 consisted of corn (14.0\%), small grains (7.6\%), soybeans (24.9\%), and sunflowers $(1.1 \%)$. Other land-uses within the study area included farmsteads $(0.9 \%)$, grassland $(27.0 \%)$, hayland $(7.2 \%)$, roads $(1.7 \%)$, trees $(1.7 \%)$, and wetland (13.8\%) (Fig. 1).

The study area is characterized by a dynamic continental climate (Kantrud et al., 1989) with a mean annual precipitation of

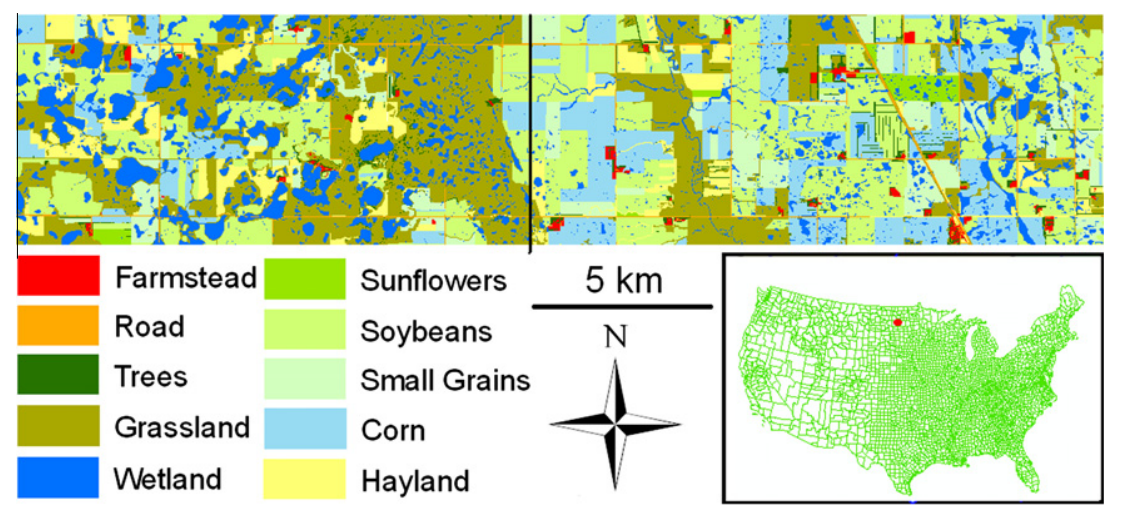

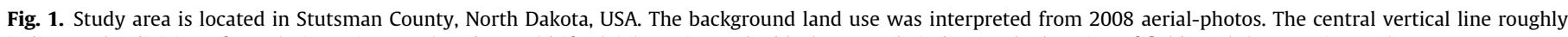
indicates the division of east (Missouri Coteau) and west (drift plain) portions. The black rectangle indicates the location of field work (see Section 4.4). 
approximately $440 \mathrm{~mm}$ (Carroll et al., 2005). Large variations in temperature and precipitation result from complex interactions among air masses that originate from polar, Pacific, and the Gulf of Mexico sources (Borchert, 1950; Bryson and Hare, 1974). Variations in temperature and moisture content of competing air masses lead to great seasonal and annual differences in precipitation and evaporation rates. Additionally, long-term cycles between periods of drought (Woodhouse and Overpeck, 1998) and deluge (Winter and Rosenberry, 1998) can dominate the climate of the region. These wet/dry climate cycles can persist for several years or even for decades (Duvick and Blasing, 1981; Karl and Koscielny, 1982; Karl and Riebsame, 1984; Diaz, 1983, 1986). Prairie wetlands are often dry during drought and fill to depths beyond the tolerance limits of most emergent vegetation during deluge (Winter and Rosenberry, 1998). During periods of deluge, wetlands situated along integrated drainage systems can contribute to flood water retention, thereby mitigating the potential of downstream flooding. Conversely, non-integrated wetlands that have become integrated through artificial drainage networks of ditches, culverts, and/or drainage tiles can add additional flows to stream and river systems, potentially exacerbating downstream flooding.

\section{Datasets}

On 17 May 2008, a LiDAR dataset was acquired by FugroHorizons using a Leica ALS-50-II sensor. The sensor was flown at an altitude of $1737 \mathrm{~m}$ above mean terrain at an average speed of $241 \mathrm{~km} / \mathrm{h}$. The flight plan allowed a 20\% overlap between adjacent swaths. The instrument was set to a 24-degree field of view, $50 \mathrm{~Hz}$ scan rate, and a pulse rate of $129,600 / \mathrm{s}$ (two pulses in the air). The laser produces a coherent beam of near infrared light at $1064 \mathrm{~nm}$. The output beam divergence is 0.22 milliradians, yielding an illuminated ground footprint diameter of approximately $0.76 \mathrm{~m}$ at nadir. Each flight line had a maximum laser hit spacing of approximately $0.91 \mathrm{~m}$ across track and $1.34 \mathrm{~m}$ along track, producing an average of $0.62 \mathrm{~m}$ post spacing for the dataset (singleswath). The LiDAR data were referenced to Universal Transverse Mercator (UTM) Zone 14N, NAD83 horizontally and NAVD88 vertically. The root mean square errors of horizontal and vertical accuracies were $12.3 \mathrm{~cm}$ and $11.3 \mathrm{~cm}$, respectively, when compared with control points located in clear and open areas. An 8-bit grayscale intensity image was simultaneously acquired at $0.5 \mathrm{~m}$ resolution.

In addition to the LiDAR dataset, we used NWI data. The NWI data were manually interpreted from 1979-1994 aerial photography at a scale of $1: 24,000-1: 25,000$ with support from soil surveys and field checking. NWI is a static dataset that does not reflect wetland temporal change; however, NWI does provide a source for wetland location information.

\section{Methodology}

\subsection{Overview}

Using the LiDAR-derived bare-earth DEM, we delineated wetland catchment polygons and identified spilling points (Section 4.2). For the basin storage modeling, we considered the aboveand below-water volume as well as basin connectivity (Section 4.3). A flowchart of our work is shown in Fig. 2. We surveyed the topography in a small area to assess the accuracy of basin storage (Section 4.4). Based upon the basin storage volumes, we defined and calculated a Basin Floodwater Regulation Index (BFRI) (Section 4.5). We demonstrated how to use the BFRI to estimate wetland floodwater mitigation potential during flood events of differing severity (Section 4.6).

\subsection{Modeling bare-earth elevation, wetland catchment, and spilling point}

The project area is generally covered by grass and crops with scattered windbreak tree lines and very small wooded areas. Last-return point data were classified into the following categories: "ground", "noise", and "non-ground" using the industry-standard TerraSolid suite of LiDAR's processing tools. Using all points identified as "ground", a bare-earth DEM was interpolated at $0.5 \mathrm{~m}$ resolution via an intermediate Delaunay triangulation, following standard industry practice. Subsequently, we used the NWI polygons to generate unique catchment for all individual NWI wetlands. To do this, we first identified the centroids of all NWI wetland polygons. We then used fill, flow direction, flow accumulation, and watershed tools from the ArcGIS hydrology toolbox to delineate catchments. During this process, we forced the flow direction model to move the hydrologic flow to the centroid pixel. Hence, we were able to create a catchment area for each NWI polygon. After each wetland catchment was delineated, the basin spilling point location and elevation were identified as the minimum LiDAR elevation along the catchment polygon boundaries.

\subsection{Wetland basin storage modeling}

The near-infrared wavelength of the LiDAR laser is absorbed by water, which prevents measurement of the basin morphology

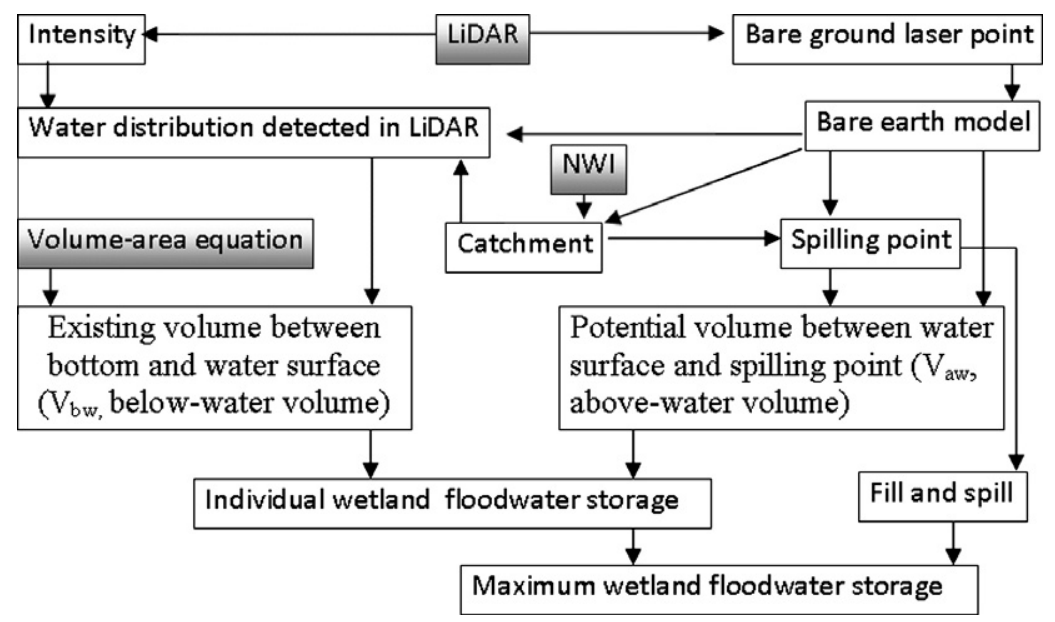

Fig. 2. Flowchart of modeling floodwater storage. 
beneath water surfaces. Our LiDAR data were acquired during a period when the water was high; therefore, the floodwater storage volume of each individual basin was composed of two parts (Fig. 3). One part is the volume below water surfaces ( $V_{\mathrm{bw}}$, Section 4.3.1) and another part is the volume between the water surfaces and spilling points ( $V_{\mathrm{aw}}$, Section 4.3.2). However, wetland routing overflow through spilling points increases the basin storage (Fig. 3); we, therefore, considered the connectivity in our modeling (Section 4.3.3).

\subsubsection{Below-water volume of individual wetland $\left(V_{b w}\right)$}

With the wetland basin morphology "hidden" under the water surface, it was not possible to calculate the exact volume beneath the existing water; however, there is a strong statistical relationship between volume $(V)$ and area $(A)$ in a topographic depression (Haan and Johnson, 1967; Ullah and Dickinson, 1979), and a general equation relating the $\mathrm{V}$ and $\mathrm{A}$ variables would assist in estimating the water volumes stored in prairie pothole wetlands (Minke, 2009; Minke et al., 2010). Gleason et al. (2007) developed equations of this kind for use with the Missouri Coteau (Eq. (1)) and the glaciated drift plains (Eq. (2)) for the depressional wetlands of our study area.

$V=0.398 A^{1.542}$

$V=0.25 A^{1.4742}$

where $A$ is in hectares and $V$ is in hectare-meters. We modified Eqs. (1) and (2) to Eqs. (3) and (4):

$V=0.398 \times[A / 10,000]^{1.542} \times 10,000$

$V=0.25 \times[A / 10,000]^{1.4742} \times 10,000$

where $A$ is the water surface area in $\mathrm{m}^{2}$ and $V$ is the water volume in $\mathrm{m}^{3}$.

To derive the area $A$ of surface water, we interpreted the water bodies from the LiDAR dataset in three steps. First, we identified the minimum LiDAR bare-earth elevation in each wetland catchment area ( $\mathrm{min}$ ) in order to determine the likely location of water since water tends to aggregate in the low areas. Second, in each catchment the elevations lower than " $\mathrm{min}+0.5$ " were identified as potential water bodies. The value of $0.5 \mathrm{~m}$ was used to aggressively model potential water since we assumed the water surface was relatively flat and the vertical accuracy of the LiDAR DEM was around $0.11 \mathrm{~m}$. Third, we excluded those pixels with a LiDAR intensity greater than 60 because the water was dark in the intensity image while non-water such as crop land showed relatively bright. When the area $(A)$ was derived, the $V-A$ Eqs. (3) and (4) were applied to calculate the water storage.

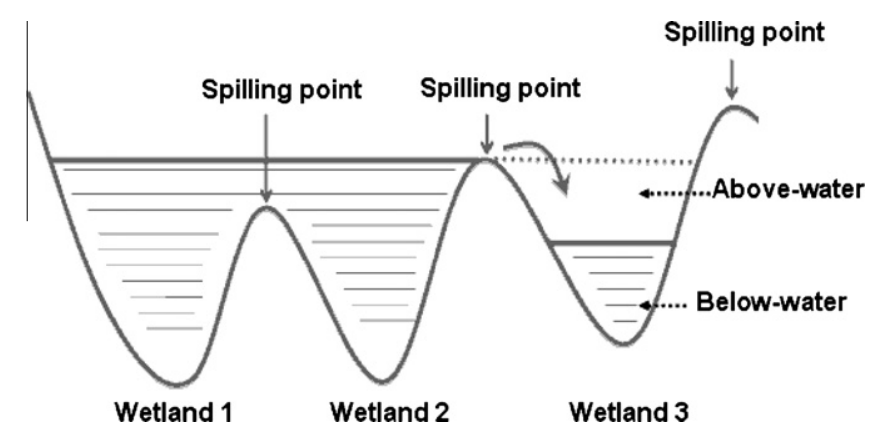

Fig. 3. Storage volume of each wetland basin has above- and below-water volume components. Wetlands can merge due to routing of overflow water through spilling points.

\subsubsection{Above-water volume of individual basins $\left(V_{a w}\right)$}

While $V-A$ relationships have been used for large scale investigations of water storage, there is concern they do not provide accurate volume estimates because the $V-A$ method does not use a wetland depth measurement to account for variation in basin morphology (Wiens, 2001; Minke, 2009; Minke et al., 2010). Therefore, for the volume between spilling point and water surface (although we can model the $A$ at spilling point for $V-A$ equation), we did not use this approach. We used the basin morphology detected from LiDAR to accurately model the storage instead. To do this, we used the ArcGIS "TIN polygon volume" tool to calculate the volumetric value. With the LiDAR bare-earth model converted as the TIN input and the wetland catchment as the polygon input, the volume below the spilling point elevation and potential water surface was calculated. During this process, each wetland catchment polygon boundary was first intersected with the LiDAR to identify the area in common between the two, and then the volume that represents the cubic area between the selected portion of the LiDAR and a horizontal plane located at the height of the spilling point was calculated.

By adding the above-and below-water volumes (i.e., $V_{\mathrm{aw}}+V_{\mathrm{bw}}$ ), we calculated the volume for each individual wetland basin.

\subsubsection{Basin storage considering routing overflow}

With a large input, the water overflows through spilling points and eventually forms a larger water body (Fig. 3). The "fill and spill" mechanism that influences water stored in basins should be taken into account in floodwater storage modeling. To do this, we investigated basin connectivity by comparing the locations of spilling points of basins that are geographically adjacent. If the spilling points of two basins referred to the same location, we merged the two catchment polygons into one new catchment polygon and then recalculated the spilling points. This procedure was repeated until no catchment polygons could be merged. The new water storage volume, which was taken as the maximum volume at the entire landscape level, was then modeled using the same approach described in Sections 4.3.1 and 4.3.2.

\subsection{Basin storage validation}

In order to assess accuracy, we used data from a topographic survey of each wetland catchment in the Cottonwood Lake Study Area (CLSA), which is internationally recognized as one of the most intensively studied wetland complexes in North America (van der Valk, 1989; Euliss and Mushet, 1996; Carroll et al., 2005). The topographic survey was conducted using a Trimble 5700 Global Positioning System (GPS) system. Real time kinematic carrier phase measurements of the GPS were conducted with sufficient detail to characterize the shape of each wetland catchment, identify natural spilling points, and calculate basin volumes. When water levels were too deep to collect survey points using the Trimble system, water depths and GPS coordinates were recorded from a boat using a weighted tape measure and a hand-held GPS unit. Based upon the surveyed data, the volume of each surveyed basin was computed from the program ForeSight (Tripod Data Systems, 1997). We compared the surveyed volume with our modeled volume to assess model accuracy.

\subsection{Basin Floodwater Regulation Index}

In PPR, some basins would be easily filled and then overflow in a small flood event; however, some deeper basins may not overflow even during a 500-years flood event. Therefore, the maximum water storage capacity of the basins, which was physically based upon spilling point, is an oversimplification. If realistic water 
inputs are not considered, the true amount of floodwater held by the wetland basins will be biased.

The balance between the maximum storage capacity and the incoming water from the corresponding catchment area is the main factor in determining whether or not basins will overflow. We divided the maximum basin volume by its corresponding catchment area to calculate Basin Floodwater Regulation Index (BFRI). BFRI indicates the rainfall intensity that a basin can regulate during a flood event assuming that all water falling in a catchment runs off into the basin (i.e., soil storage capacity is ignored). For example, if a basin can hold $300,000 \mathrm{~m}^{3}$ of water while the catchment area is $200,000 \mathrm{~m}^{2}$, then the BFRI is around $1500 \mathrm{~mm}$, implying that this basin can regulate $1500 \mathrm{~mm}$ intensive precipitation during a flood event. On the another hand, if a basin can hold $450 \mathrm{~m}^{3}$ water while the catchment area is $28,000 \mathrm{~m}^{2}$, then the BFRI is around $16 \mathrm{~mm}$, implying that this basin can only regulate $16 \mathrm{~mm}$ precipitation during a flood event. Considering the basin overflow connectivity mechanism, we calculated the maximum BFRI when the wetlands are dry.

\subsection{Peak-regulation capability under flood event}

When the wetland is not antecedently empty, some spaces are already occupied and cannot be used for storing floodwater. Thus, the volume that is already occupied by the existing water must be excluded when estimating flood water mitigation potential based upon the BRFI approach. To demonstrate this, we took the water level that was detected in 17 May 2008 LiDAR as an example. We first divided the $V_{\mathrm{aw}}$, which indicates how much volume is still available for further floodwater storage, by its corresponding catchment area to calculate an actual BFRI (BFRI ${ }_{17 \text { May2008). Under }}$ this scenario, we calculated how much water $(\mathrm{V})$ would be held by each wetland polygon $\left(V_{i}\right)$ under different flood events $(P$, precipitation or snow melt, ranging from $50 \mathrm{~mm}$ to $1500 \mathrm{~mm}$ with an interval of $50 \mathrm{~mm}$ ) using the following equations:

$V=\sum_{i=1}^{n} V_{i}$

$V_{i}=\left\{\begin{array}{cc}V_{\mathrm{aw}} & \left(\mathrm{BFRI}_{17 \mathrm{May} 2008}<P\right) \\ A * P & \left(\mathrm{BFRI}_{17 \text { May2008 }} \geqslant P\right) .\end{array}\right.$

where $V_{\mathrm{aw}}$ is the above-water volume considering overflow routing (see Sections 4.3.2 and 4.3.3), and $A$ is the catchment area of the corresponding basin. When $B F R I_{17 M a y 2008}$ is less than $P$, it indicates the wetland would spill and overflow, and only $V_{\mathrm{aw}}$ can be used for further holding floodwater; When BFRI ${ }_{17 \text { May2008 }}$ is equal to or greater than $P$, it indicates the wetland would not spill, and all water in
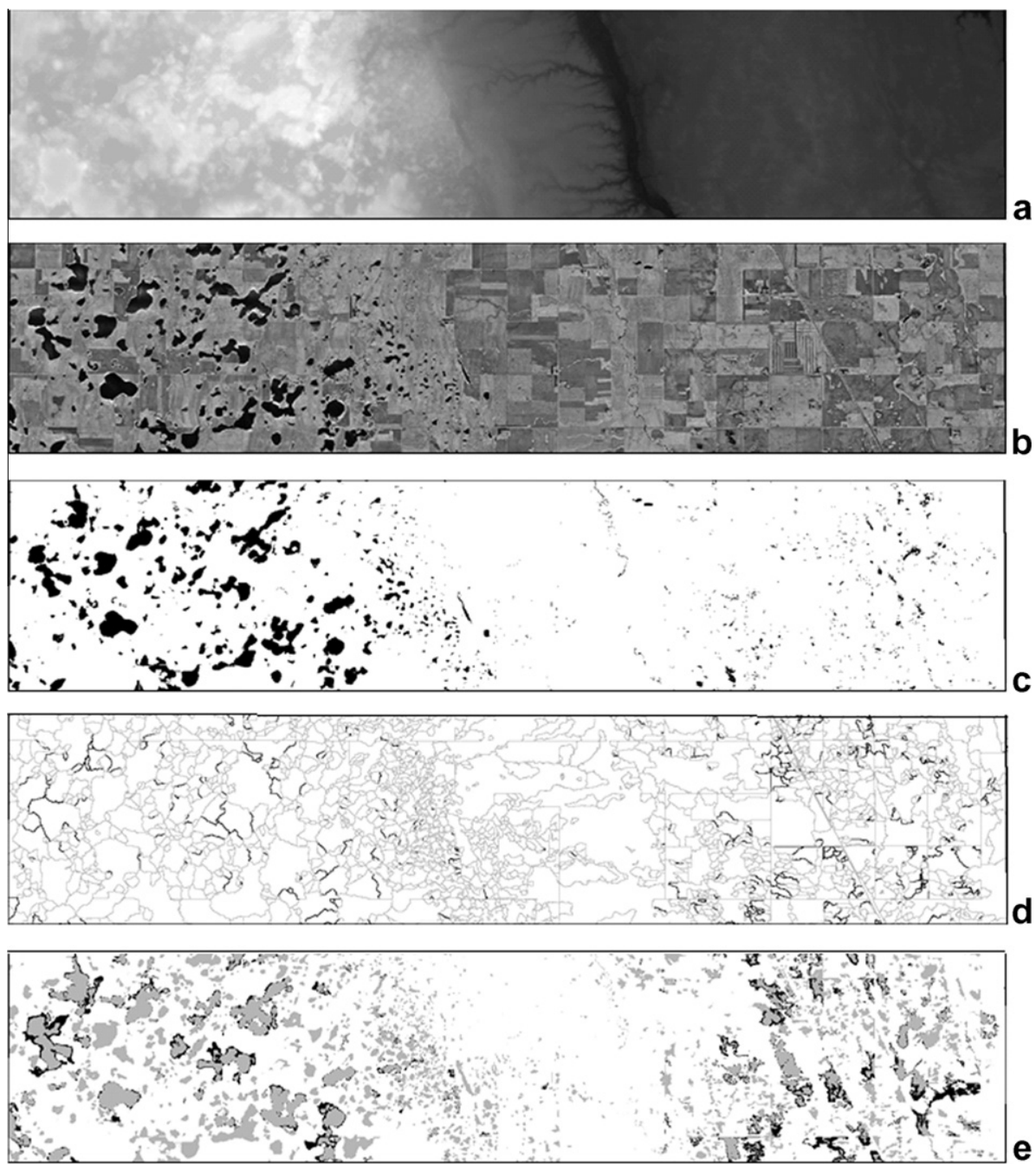

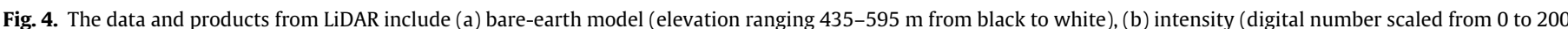

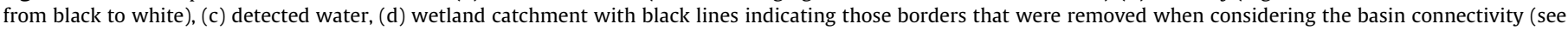

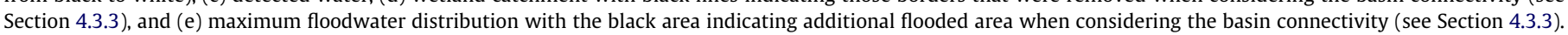


the basin (i.e., $A \times P$ ) would be kept by the wetland and out of the downstream contribution.

After $V\left(\right.$ in $\left.\mathrm{m}^{3}\right)$ is calculated, the relative percentage of the water that could be held by wetlands was inferred as:

Percentage $=\frac{V}{(P / 1000) * 6400 * 30,600}$

where 1000 was used to convert $P$ from $\mathrm{mm}$ to $\mathrm{m}$ while $6400 \times 30,600$ indicated the total land area (in unit of $\mathrm{m}^{2}$ ) of the study site.

\section{Result}

Different products from our study are shown in Fig. 4. The minimum and maximum elevations in this study area were 435.69 and $596.26 \mathrm{~m}$, respectively, with a mean elevation of 509.90 and standard deviation of $42.99 \mathrm{~m}$. The west side of our study area was higher and rougher than the eastern side; the area is divided by a small low-elevation creek flowing from the northwest to the southeast (Fig. 4a). The existing water bodies showed very dark in the LiDAR intensity image, while the cropland and upland grassland were brighter (Fig. 4b); however, some small, patchy, groundvalidated burnt land and trees also showed as darkly as water. Using our approach, we identified 2245 unique basins, 1375 of which contained water. The surface area of the largest water body was $849,750 \mathrm{~m}^{2}$ and the total water surface area was around 15.03 million $\mathrm{m}^{2}$ (Fig. 4c). We estimated that these existing water bodies contained approximately 32.65 million $\mathrm{m}^{3}$ of water and the 2245 basins could hold 52.44 million $\mathrm{m}^{3}$ of floodwater in total, which includes existing water. When basin connectivity was considered, 413 catchment polygons were merged and the total volume increased to 80.24 million $\mathrm{m}^{3}$ (Fig. $4 \mathrm{~d}$ and $4 \mathrm{e}$ ). It should be reiterated that the 80.24 million $\mathrm{m}^{3}$ volume is a quantification of the maximum storage capacity of these basins and is not a quantification of how much of this maximum capacity would realistically be filled during a major flood event (see BFRI below).

Fig. 5 shows the field measurements where 29,733 survey points were in upland and 138 in water, respectively. Of 11 modeled spilling points, 10 matched the observed spilling points very well in location with a Mean Absolute Error (MAE) of around $5 \mathrm{~m}$; however, one modeled spilling point was $188 \mathrm{~m}$ from its true observed location. The LiDAR elevation of this ground-truth spilling point was $578.51 \mathrm{~m}$ while that of the modeled one was $578.38 \mathrm{~m}$, a difference of only $13 \mathrm{~cm}$. This slight difference might

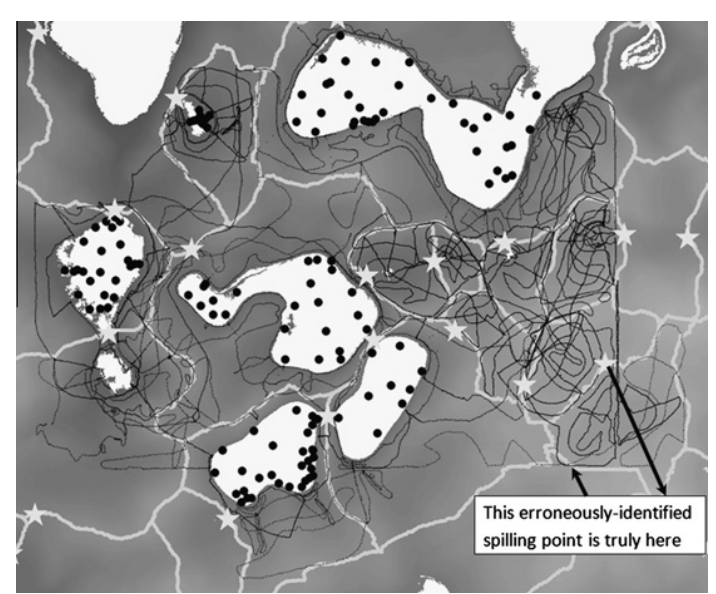

Fig. 5. Field survey GPS points and spilling points. The small black points were collected in upland areas, large black points were surveyed in the water (white polygons), while the thick white lines were catchment borders modeled from LiDAR bare-earth model (background gray image).

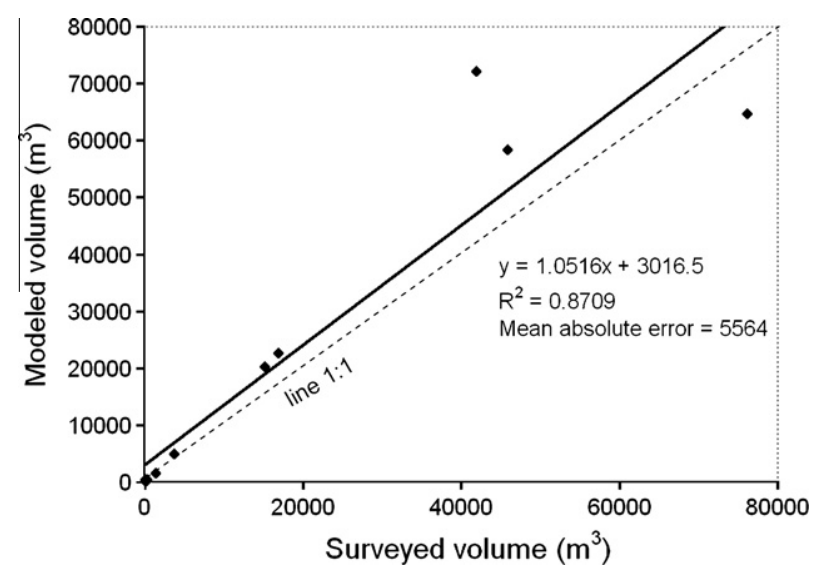

Fig. 6. Comparison between surveyed and modeled floodwater storage volume.

be accounted for by LiDAR noise and grass whose return signatures could be erroneously contained in the LiDAR bare-earth model. Regarding the storage volume of the 11 wetlands: the comparison between observed and modeled floodwater storage had an $R^{2}$ value of 0.87 (Fig. 6) with a MAE of $5564 \mathrm{~m}^{3}$.

Fig. 7a shows the general distribution of the BFRI over the entire landscape assuming all wetland are dry. On the west side of Missouri Coteau, $56 \%$ the land area was covered by those wetlands with BFRI greater than $200 \mathrm{~mm}$; in contrast, on the east side of drift plain, only $5 \%$ the land area was covered by those wetlands with BFRI greater than $200 \mathrm{~mm}$. The higher BFRI on the west side indicates that the relatively deep basins of the Missouri Coteau are less likely to contribute to downstream flooding than those of the drift plain.

However, wetlands are typically not dry at the beginning of a flood event, which can result in a reduced capability of a wetland to store floodwater. For example, when the LiDAR was acquired (May 17, 2008), an estimated 32.65 million $\mathrm{m}^{3}$ water already existed in the wetland (Fig. 4c). When this filled capacity is excluded (Fig. $7 \mathrm{~b}$ ), we can see that $48 \%$ of the area on the west side and $5 \%$ of the area on the east side has BFRI scores greater than $200 \mathrm{~mm}$; this implies that these lands would still prevent runoff from contributing to streamflow during a $200 \mathrm{~mm}$-equivalence snowmelt or storm event.

With the existing water detected on 17 May 2008 LiDAR excluded, Fig. 8 shows the water that could be held by the wetland basins increased from 6 to 46 million $\mathrm{m}^{3}$ when the precipitation increased from 50 to $1500 \mathrm{~mm}$. However, when the precipitation is above $1000 \mathrm{~mm}$, the water volume held by wetland basins could only increase very slightly. Furthermore, while the absolute water volume held by the basins increased with precipitation, the relative percentage of the water held correspondingly decreased from $63 \%$ to $15 \%$ when the precipitation increased from 50 to $1500 \mathrm{~mm}$.

\section{Discussion}

LiDAR, using the round-trip time of emitted laser light to measure ground distances from an aircraft, has been widely applied to acquire high-resolution DEMs for large areas. With high-resolution DEMs available, the catchments and spilling points of basins in the PPR (an area of extremely low relief), can be modeled. Researchers are, therefore, able to estimate the water storage capacity of individual basins as well as identify connectivity. This allows the quantification of storage capacity and the depiction of spatially-explicit water storage. The maps generated from our research can be used to help solve some flood issues. For example, the maximum water distribution map (Fig. 4e) indicates the locations of water extent 

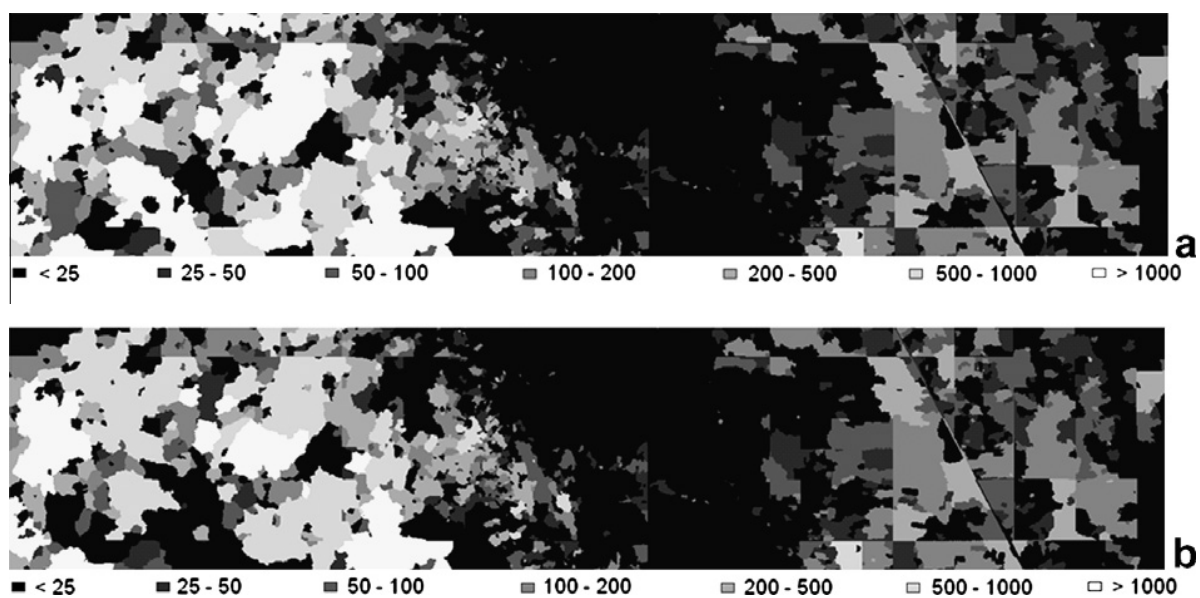

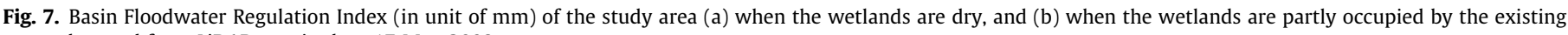
water detected from LiDAR acquired on 17 May 2008.

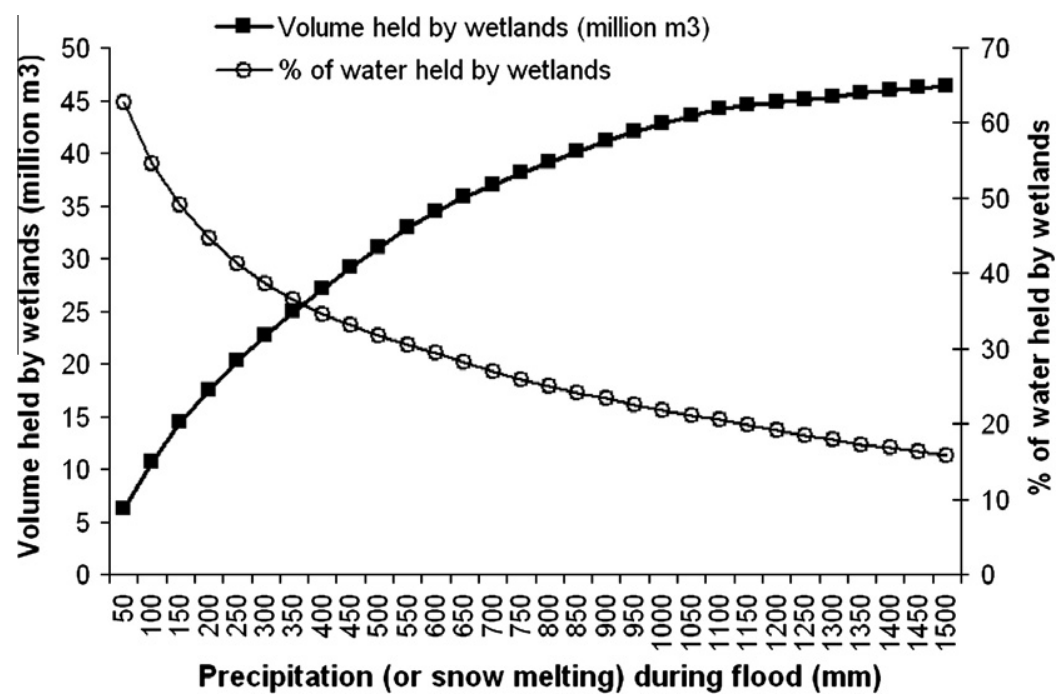

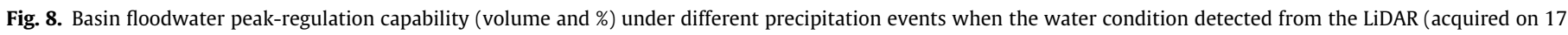
May 2008) was excluded.

when wetlands fill and merge, and thus can be used for localized flood risk assessment. The BFRI map (Fig. 7) shows the capability of different wetlands to mitigate downstream flooding in its corresponding catchment. This can help determine the priority of wetland protection and restoration for flood control service. With LiDAR data becoming more readily available due to reduced costs and improving technology, the use of high-resolution LiDAR data to estimate floodwater storage potential is promising; however, several issues must be considered.

First, the most common product derived from airborne LiDAR is a "traditional" topographic DEM, which includes bridges, roads over culverts, and other apparent obstructions to water flow. These obstructions and culverts can greatly affect flow dynamics, and make continuous surface flow extraction very challenging (Poppenga and Worstell, 2008). For hydrologic modeling, it is preferable to develop a "hydrologic" DEM that is tailored to allow the surface to represent how and where water actually flows. Some automatic or semi-automatic approaches (e.g., selective drainage methods, Poppenga et al., 2010) need be explored for a large area application to improve the estimation of wetland basin storage.

Second, with available detailed topographic information, methods exist to quantify water volume for depressional wetlands. A bathymetric (or topo-bathy) LiDAR instrument that is designed to penetrate water would likely be highly effective at mapping the true bottom of shallow ponds (Wang and Philpot, 2007). However, typical airborne topographic LiDAR systems, operating in the near-infrared spectrum (1064 nm), are neither designed nor are capable of collecting bathymetric data. If the volume of the existing water is not considered, the maximum capacity of basins would be underestimated. For this reason, Minke (2009) suggested that LiDAR data be acquired in dry years when pond water levels are very low; however, the water levels of wetlands in our study area (except small wetlands) have been remained high due to relatively wet weather since 1992; obviously, we cannot anticipate when the wetlands will be dry again. Therefore, in this paper we provide a solution to this LiDAR water-penetration problem of floodwater storage modeling by extracting the water, calculating its surface area, and then using a surface area to volume equation (e.g., Gleason et al., 2007) to estimate its volume. Because the intensity image is acquired simultaneously with the LiDAR, it can be used to delineate water bodies, which usually appear as relatively dark. However, some non-water features (such as burned grass) may be also dark, making a simple automatic intensity threshold-value approach unreliable (Fig. 9). In order to improve 

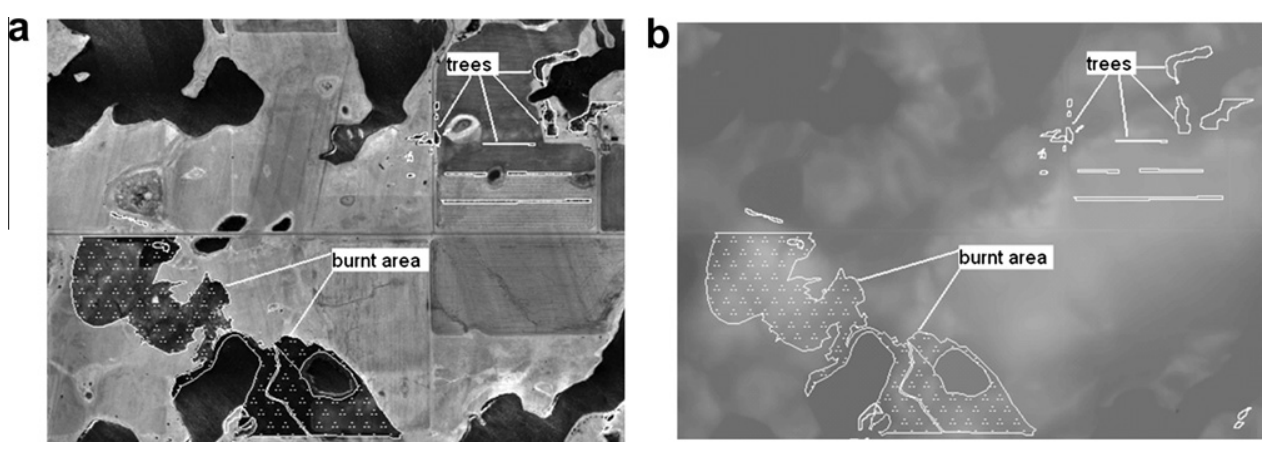

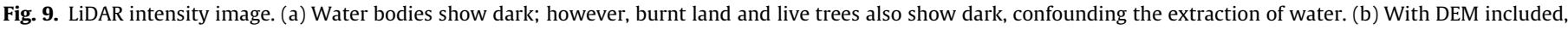
the classification can be improved (see Section 4.3.1).

the classification accuracy, we also considered that wetland water bodies typically have flat and level surfaces. The minimum elevation of each catchment, plus $0.5 \mathrm{~m}$, was thus used to automatically identify the potential water bodies within the DEM; this classification was refined by excluding pixels with intensity values greater than the threshold value. While "water is relatively dark" proved to be effective in our study area, other studies may require attention, because water sometimes may exhibit bright due to suspended sediment or biotic material (e.g. algae).

Third, considering the strong relationship between area and volume (Haan and Johnson, 1967), attempts have been made to estimate wetland volume from wetland area alone. Volume-area $(V-A)$ relationships are commonly used because storage can be easily estimated for large areas. This method involves field surveying limited wetlands to derive a regression equation that statistically relates area to volume and then uses the relationship along with remote sensing-derived area measurements to estimate volume at the watershed scale (Haan and Johnson, 1967; Wiens, 2001; Gleason et al., 2007; Minke, 2009; Minke et al., 2010). By applying the equation of Gleason et al. (2007), which was developed for our study area, we could estimate the below-water volume of a wetland; however, this equation is meant for application to a population of wetlands throughout a physiographic region; it won't necessarily predict accurate volumes for a specific wetland because of the associated variation. Wiens (2001) also stated that the $V-A$ approach is primarily useful for calculating wetland water storage for an entire watershed and is extremely limited for estimating individual wetland volumes because the $V-A$ method does not use a measurement of wetland depth to account for variation in basin morphology. In our study, the volume of a water body surveyed from a field survey was around $33,237 \mathrm{~m}^{3}$; however, the volume from Gleason's $V-A$ equation was around $39,998 \mathrm{~m}^{3}$, which indicates the deficiency of this approach. In order to estimate the wetland volume more accurately and reliably, we suggest acquiring another LiDAR dataset during a drought period.

Fourth, the wetland capability of regulating flood peak runoff is not realistic, if the actual floodwater storage and the potential catchment contribution are not simultaneously considered. In our current study, we defined BFRI when all wetlands are assumed to be empty. We also demonstrated an actual BFRI using water area data collected on 17 May 2008. Data acquired on a single day are not sufficient to accurately predict the storage capacity at other times. For decision-making in realistic flood disaster assessments, the antecedent water volume that already occupies the wetlands immediately prior to a flood event must be considered. Only with such information on antecedent conditions can the absolute and relative water that could be held by basins over a landscape be accurately estimated. Remote sensing based models may provide a means to monitor/simulate the water dynamics of the PPR wet- lands and thereby provide the antecedent water area conditions needed for accurate floodwater mitigation estimates.

The PPR wetlands are relatively small in size, lie within small isolated, topographic depressions, are generally underlain by glacial till of low permeability, and occur primarily in a semiarid climate (Winter and Rosenberry, 1995). Average annual evaporation has been estimated to be nearly twice as much as precipitation (Kohler et al., 1959), and evapotranspiration is the single largest loss of water from most prairie wetlands (Rosenberry et al., 2004). Water level fluctuation in the region is a product of the interaction of snowmelt, storm runoff, direct precipitation, evapotranspiration, seepage inflow and outflow (Millar, 1971; Johnson et al., 2005). During extremely wet and dry water years, the groundwater system may become increasingly important to the wetland stage (Carroll et al., 2005). Millar (1971) further found that shoreline-related water loss accounts for a considerable portion of the water loss in small sloughs, because greater and more rapid warming of the shallow water in such sloughs accelerates the rate of evapotranspiration from the water surface and emergent vegetation (Eisenlohr, 1966). All these studies enable us to better understand the hydrological process and mechanism of water level fluctuations; however, the ability to transfer results from sitespecific studies to landscape is one of the most asked questions in science (Rosenberry et al., 2004). With the high-resolution LiDAR DEM, wetland morphology, and water routing retrieved from this study, we may quantify the contribution of these factors for a given set of climatic, soil and physiographic conditions, then it should be possible to predict water levels at specific time steps (e.g., daily) (Millar, 1971). We have been studying remote sensing and hydrology models to monitor and predict the antecedent depressional storage; those results will be reported in a separate paper. This will provide a more realistic picture of how much water is stored during a flood event and the overall water dynamics of the PPR. Not only does this benefit the floodwater management, it is also critical to understanding vegetation change, wildlife conservation, carbon sequestration, and green-house gas emission in the PPR.

\section{Conclusion}

LiDAR has shown its utility for resolving subtle landscape features by providing very high-resolution, high accuracy DEMs that capture detailed wetland morphology even in areas of extremely low relief. This allows the catchment area and spilling point of each wetland to be modeled accurately, as well as the above-water volume between the existing water surface and spilling point. However, the below-water volume between wetland bottom and existing water surface cannot be computed directly due to the limited water penetration capability of topographic LiDAR systems. A semi-empirical model, which incorporates water surface area, has 
to be considered to predict the volume. Therefore, it is important to identify water bodies from the LiDAR data. Using the LiDAR DEM in conjunction with its associated intensity image, water bodies can be classified while reducing confounding factors such as fire scars and live trees. With the above-water and below-water volume of each wetland taken into account, it is feasible to compute the water volume for each wetland basin; however, the wetland connectivity through the overflow mechanism should also be considered for improving the estimation. Since some wetland basins easily fill and then overflow while others do not overflow even during a 500-years flood event, BFRI is a useful tool for flood assessments. It can be used to directly assess the capacity of wetlands drainage or restoration on floodwater control. The spatially explicit maps generated from this study are based upon the maximum storage and BFRI that assumes $100 \%$ runoff within a catchment during a flood event. Runoff amounts clearly are less than this and vary by land-use type and topography. To improve realism, more accurate estimates of precipitation runoff under various land-use and topographic conditions are needed. However, the maps we provide here offer an example of their potential use in flood risk analysis and risk reduction planning. If the water level at the beginning of flood is available, the absolute and relative water held by wetland basins over a landscape could be inferred.

In addition to refinement of the BFRI using land-use and topographic information, several other issues require more attention to improve floodwater mitigation modeling. As noted earlier, typical airborne topographic LiDAR systems cannot reliably penetrate water, and bathymetric (or topo-bathy) LiDAR systems were not readily available in this study. One solution to estimate the existing water volume is to use a $V-A$ equation, which has some deficiencies. Despite the bias, the $V-A$ equations have been locally developed for PPR (e.g., Hayashi and van der Kamp, 2000; Gleason et al., 2007; Minke et al., 2010) and much LiDAR data have been collected for the PPR (http://lidar.cr.usgs.gov/LIDAR_Viewer/viewer. $\mathrm{php}$ ); therefore, our approach to estimate floodwater storage is promising. Most importantly, a framework of integrating remote sensing and hydrological process model is critical for predicting the water level at the beginning of a flood event. This would aid a better evaluation on the flood-water attenuation service of PPR wetlands.

\section{Acknowledgements}

This work was supported by US Department of Agriculture's Conservation Effects Assessment Program (CEAP)-Wetlands, the US Geological Survey's Geographic Analysis and Monitoring (GAM), and the Global Change Research and Development Programs. The authors greatly thank Dr. Robert Gleason and Mr. Brian Tangen for data analysis support. The authors also give special thanks to Dr. Yiping Wu, Dr. Suming Jin, and Dr. Larry Tieszen for their constructive comments and Mr. Craig Walters for improving the English. Any use of trade, product, or firm names is for descriptive purposes only and does not imply endorsement by the US Government.

\section{References}

Borchert, J.R., 1950. The climate of the central North American grassland. Ann. Assoc. Am. Geogr. 40, 1-39.

Bryson, R.A., Hare, F.K., 1974. Climates of North America. In: Landsberg, H.E. (Ed.) World Survey of Climatology, vol. 11. Elsevier, New York, pp. 1-47.

Carroll, R.W., Pohll, G.M., Tracy, J., Winter, T., Smith, R., 2005. Simulation of a semipermanent wetland basin in the Cottonwood Lake Area, East-Central North Dakota. J. Hydrol. Eng. 1 (10), 70-84.

Dahl, T.E., 1990. Wetlands Losses in the United States 1780's to 1980's. US Department of the Interior, Fish and Wildlife Service, Washington, DC, p. 13
Dahl, T.E., Johnson, G.E., 1991. Status and Trends of Wetlands in the Conterminous United States, mid-1970s to mid-1980s. US Department of the Interior, Fish and Wildlife Service, Washington, DC, p. 28.

Diaz, H.F., 1983. Some aspects of major dry and wet periods in the contiguous United States, 1895-1981. J. Clim. Appl. Meteorol. 22, 3-16.

Diaz, H.F., 1986. An analysis of twentieth century climate fluctuations in northern North America. J. Clim. Appl. Meteorol. 25, 1625-1657.

Duvick, D.N., Blasing, T.J., 1981. A dendroclimatic reconstruction of annual precipitation amounts in Iowa since 1680. Water Resour. Res. 17, 1183-1189.

Eisenlohr Jr., W.S., 1966. Water loss from a natural pond through transpiration by hydrophytes. Water Resour. Res. 2, 443-453.

Euliss Jr., N.H., Mushet, D.M., 1996. Water-level fluctuation in wetlands as a function of landscape condition in the prairie pothole region. Wetlands 16 (4), 587-593.

Fang, X., Pomeroy, J.W., 2008. Drought impacts on Canadian prairie wetland snow hydrology. Hydrol. Process. 22, 2858-2873.

Gleason, R.A., Tangen, B.A., 2008. Floodwater storage. In: Gleason, R.A., Laubhan, M.K., Euliss, N.H., Jr. (Eds.), Ecosystem Services Derived from Wetland Conservation Practices in the United States Prairie Pothole Region with an Emphasis on the US Department of Agriculture Conservation Reserve and Wetlands Reserve Programs. US Geological Survey, Reston, VA, USA. Professional Paper No. 1745, pp. 31-37 (Chapter D).

Gleason, R.A., Tangen, B.A., Laubhan, M.K., Kermes, K.E., Euliss, N.H., Jr., 2007. Estimating Water Storage Capacity of Existing and Potentially Restorable Wetland Depressions in a Subbasin of the Red River of the North. US Geological Survey Open-File Rep. 2007-1159, p. 36.

Godwin, R.B., Martin, F.R.J., 1975. Calculation of gross and effective drainage areas for the Prairie Provinces. Proc. Can. Hydrol. Symp. 1975, 219-223.

Haan, C.T., Johnson, H.P., 1967. Geometric properties of depressions in NorthCentral Iowa. Iowa State J. Sci. 42, 149-160.

Hayashi, M., van der Kamp, G., 2000. Simple equations to represent the volumearea-depth relations of shallow wetlands in small topographic depressions. J. Hydrol. 237, 74-85.

Hayashi, M., van der Kamp, G., Schmidt, R., 2003. Focused infiltration of snowmelt water in partially frozen soil under small depressions. J. Hydrol. 270, 214-229.

Hubbard, D.E., Linder, R., 1986. Spring runoff retention in prairie pothole wetlands. J. Soil Water Conserv. 41, 122-125.

Johnson, W.C., Millett, B.V., Gilmanov, T., Voldseth, R.A., Guntenspergen, G.R., Naugle, D.E., 2005. Vulnerability of Northern Prairie wetlands to climate change. Bioscience 55, 863-872.

Kantrud, H.A., Krapu, G.L., Swanson, G.A., 1989. Prairie Basin Wetlands of the Dakotas: A Community Profile. US Fish Wildl. Serv. Biol. Rep. No. 85, p. 116.

Karl, T.R., Koscielny, A.J., 1982. Drought in the United States: 1895-1981. J. Clim. 2, 313-329.

Karl, T.R., Riebsame, W.E., 1984. The identification of 10 to 20 year temperature and precipitation fluctuations in the contiguous United States. J. Clim. Appl. Meteorol. 23, 950-966.

Kohler, M.A., Nordenson, T.J., Baker, D.R., 1959. Evaporation Maps for the United States: US Weather Bureau Technical Paper No. 37

LaBaugh, J.W., Winter, T.C., Rosenberry, D.O., 1998. Hydrologic functions of prairie wetlands. Great Plains Res. 8, 17-37.

Millar, J.B., 1971. Shoreline-area ratio as a factor in rate of water loss from small sloughs. J. Hydrol. 14 (3-4), 259-284.

Minke, A., 2009. Estimating Water Storage of Prairie Pothole Wetlands. Thesis of Master, University of Saskatchewan, Canada.

Minke, A.G., Westbrook, C.J., van der Kamp, G., 2010. Simplified volume-areadepth method for estimating water storage of Prairie Potholes. Wetlands 30, 541-551.

Poppenga, S.K., Worstell, B.B., 2008. Elevation-derived Watershed Basins and Characteristics for Major Rivers of the Conterminous United States. US Geological Survey Scientific Investigations Report No. 2008-5153, p. 2.

Poppenga, S.K., Worstell, B.B., Stoker, J.M., Greenlee, S.K., 2010. Using Selective Drainage Methods to Extract Continuous Surface Flow from 1-meter LiDARderived Digital Elevation Data. US Geological Survey Scientific Investigations Report No. 2010-5059, p. 12.

Rannie, W.F., 1980. The Red River flood control system and recent flood events. Water Resour. Bull. 16, 207-214.

Rosenberry, D.O., Stannard, D.I., Winter, T.C., Martinez, M.L., 2004. Comparison of 13 equations for determining evapotranspiration from a prairie wetland, Cottonwood Lake area, North Dakota, USA. Wetlands 24 (3), 483-497.

Sethre, P.R., Rundquist, B.C., Todhunter, P.E., 2005. Remote detection of Prairie Pothole ponds in the Devils Lake Basin, North Dakota. GISci. Remote Sens. 42 (4), 277-296.

Tripod Data Systems, 1997. ForeSight for Windows. Tripod Data Systems, Inc., Corvallis, OR.

Ullah, W., Dickinson, W.T., 1979. Quantitative description of depression storage using a digital surface model, II. Characteristics of surface depressions. J. Hydrol. $42,77-90$.

van der Kamp, G., Hayashi, M., 2009. Groundwater-wetland ecosystem interaction in the semiarid glaciated plains of North America. J. Hydrogeol. 17, 203-214.

van der Valk, A.G. (Ed.), 1989. Northern Prairie Wetlands. Iowa State University Press, Ames, IA, p. 400.

Wang, C., Philpot, W.D., 2007. Using airborne bathymetric LiDAR to detect bottom type variation in shallow waters. Remote Sens. Environ. 106 (1), 123-135.

Wiens, L., 2001. Surface area-volume relationships for prairie wetlands in the upper Assiniboine river basin, Saskatchewan. Can. J. Water Resour. 26, 503-513. 
Winter, T.C., 1989. Hydrologic studies of wetlands in the northern prairie. In: van der Valk, A.G. (Ed.), Northern Prairie Wetlands. Iowa-State University Press, Ames, IA.

Winter, T.C., LaBaugh, J.W., 2003. Hydrologic considerations in defining isolated wetlands. Wetlands 23 (3), 532-540.

Winter, T.C., Rosenberry, D.O., 1995. The interaction of ground water with prairie pothole wetlands in the Cottonwood Lake area, east-central North Dakota, 1979-1990. Wetlands 15, 193-211.

Winter, T.C., Rosenberry, D.O., 1998. Hydrology of prairie pothole wetlands during drought and deluge: a 17-year study of the Cottonwood Lake wetland complex in North Dakota in the perspective of longer term measured and proxy hydrological records. Clim. Change 40, 189-209.

Winter, T.C., Benson, R.D., Engberg, R.A., Wiehe, G.J., Emerson, D.G., Crosby, O.A. Miller, J.E., 1984. Synopsis of Ground-water and Surface-water Resources of North Dakota. US Geological Survey Open File Report No. 84-732.

Woodhouse, C.A., Overpeck, J.T., 1998. 2000 years of drought variability in the central United States. Bull. Am. Meteorol. Soc. 79, 2693-2714.

Zhang, B., Schwartz, F.W., Liu, G., 2009. Systematics in the size structure of prairie pothole lakes through drought and deluge. Water Resour. Res. 45 (4), W04421. 